\title{
COMPARISON OF TOLERABILITY BETWEEN QUETIAPINE AND HALOPERIDOL IN SCHIZOPHRENIA
}

\author{
Koirala, Naba Raj; Chapagain, Manisha; Tulachan, Pratikchya and \\ Zafreeen, Siquafa
}

\begin{abstract}
:
Schizophrenia is a serious, disabling, often lifetime condition, which can produce severe functional impairment in patients. The life time morbidity risk for schizophrenia is estimated to be $1 \%$ and account for $2.8 \%$ of the total global YLDs. The World Health Organization Assessment Instrument for Mental Health Systems report of 2006 done in Nepal states in Nepal states that 12\% of the patients are diagnosed as schizophrenia in out-patient mental facilities, $14 \%$ in community based psychiatry inpatient units and $34 \%$ in mental hospital . Atypical antipsychotics are the first line agents recommended for the treatment of schizophrenia considering better efficacy at least in the negative symptoms and better side-effect profile compared with typical antipsychotic. Haloperidol has been used as a standard comparator in numerous trials and new drugs have been compared to it to establish their efficacy, and safety profile. As the authors could not find out any such study which had compared the safety profile of quetipine against conventional antipsychotic, hence this present study is purposed to carry as an attempt to address this issue among Nepalease population.
\end{abstract}

Key words: quetiapine, haloperidol, Tolerability, Schizophrenia.

\section{Introduction:}

In the modern pharmacology, two broad groups of antipsychotics are recognizedconventional antipsychotics (CAP) and atypical antipsychotics (AAP). Before any antipsychotic can be accepted as useful, its relative merits in comparison with the existing drugs must be carefully accessed. There are various studies which provide evidence that Quetiapine is as effective as conventional antipsychotic agents in treating positive symptoms and more effective in the treatment of negative symptoms of schizophrenia. Quetiapine is found to be more tolerable in most trials and has led to better outcomes in terms of better rehabilitation, drop in in-patients and crisis utilization, increased vocational training, increased compliance and medication visits, decreased hospitalization, and with overall decrease in indirect health costs which 
offsets the direct acquisition costs leading to stabilization at a lower level of health care expenditure $^{1,2}$.

Tolerability is a key factor in treatment adherence, which is important to the long term outcome for patients with schizophrenia. From a pharmacoecomomic perspective, non adherence is also costly leading to increase in external service costs and a requirement for more in patient services for patients who fail to adhere. The side effect profile is equally important as the efficacy, because the short term and long term outcomes of the drug might make the patient worse than the disease $\mathrm{e}^{2,3,4}$.

\section{Metods and Methodology:}

This study sought to compare the sideeffects of quetiapine and haloperidol in schizophrenia patients. The study enrolled 45 patients both from OPD and inpatient of Psychiatry department TUTH between Jan and July 2009. Those meeting the ICD-10 DCR criteria for schizophrenia were randomly assigned to quetiapine (600$800 \mathrm{mg} /$ day) and haloperidol (15-20 mg/day) after informed consent. Patients were either drug naïve or washout period of one week was given. Patients were evaluated at $0,7,14$, 28 and 42 days of intervention using UKU side-effect rating scale. Those patients developing extra pyramidal side- effects were treated with Trihexyphenidy and Promethazine and benzodiazepines were used as needed to control aggression and sleep disturbances.

\section{Results:}

Table I: Psychic side-effects observed in both the groups during the study group

\begin{tabular}{|l|l|l|l|l|l|}
\hline Adverse Effect & \multicolumn{3}{|c|}{ Haloperidol } & \multicolumn{3}{c|}{ Quetiapine } & T- test \\
\hline Psychic & Present & Absent & Present & Absent & \\
\hline $\begin{array}{l}\text { Concentration } \\
\text { difficulties }\end{array}$ & $2(11.1 \%)$ & $16(88.9 \%)$ & $(5 \%)$ & $19(95 \%)$ & \\
\hline Asthenia & $10(55.6 \%)$ & $8(44.4 \%)$ & $(15 \%)$ & $17(85 \%)$ & $\mathrm{P}=0.485$ \\
\hline Sleeping & $4(22.2 \%)$ & $14(77.8 \%)$ & $(45 \%)$ & $11(55 \%)$ & $\mathrm{P}=0.009^{*}$ \\
\hline Failing Memory & $0(0 \%)$ & $18(100 \%)$ & $0(0 \%)$ & $20(100 \%)$ & $\mathrm{NS}$ \\
\hline Depression & $0(0 \%)$ & $18(100 \%)$ & $0(0 \%)$ & $0(100 \%)$ & $\mathrm{NS}$ \\
\hline Tension & $3(16.7 \%)$ & $15(83.3 \%)$ & $0(0 \%)$ & $20(100 \%)$ & $\mathrm{P}=0.057$ \\
\hline $\begin{array}{l}\text { Increased } \\
\text { duration of sleep }\end{array}$ & $1(5.6 \%)$ & $17(94.4 \%)$ & $(35 \%)$ & $13(65 \%)$ & $\mathrm{P}=0.026^{*}$ \\
\hline $\begin{array}{l}\text { Reduced } \\
\text { duration of sleep }\end{array}$ & $0(0 \%)$ & $18(100 \%)$ & $0(0 \%)$ & $20(100 \%)$ & $\mathrm{NS}$ \\
\hline $\begin{array}{l}\text { Increased dream } \\
\text { activity }\end{array}$ & $0(0 \%)$ & $18(100 \%)$ & $0(0 \%)$ & $0(100 \%)$ & $\mathrm{NS}$ \\
\hline $\begin{array}{l}\text { Emotional } \\
\text { Indifference }\end{array}$ & $0(0 \%)$ & $18(100 \%)$ & $0(0 \%)$ & $20(100 \%)$ & $\mathrm{NS}$ \\
\hline
\end{tabular}


Table II: neurological side-effects observed in both the groups during the study

\begin{tabular}{|l|l|l|l|l|l|}
\hline Adverse Effect & \multicolumn{2}{|c|}{ Haloperidol } & \multicolumn{2}{c|}{ Quetiapine } & T- test \\
\hline Neurological & Present & Absent & Present & Absent & \\
\hline Dystonia & $6(33.3 \%)$ & $12(66.7 \%)$ & $0(0 \%)$ & $20(100 \%)$ & $\mathrm{P}=0.005^{*}$ \\
\hline Rigidity & $13(72.2 \%)$ & $5(27.8 \%)$ & $0(0 \%)$ & $20(100 \%)$ & $\mathrm{P}=0.000^{*}$ \\
\hline Hypokinesia & $7(38.9 \%)$ & $11(61.1 \%)$ & $1(5 \%)$ & $19(95 \%)$ & $\mathrm{P}=0.011^{*}$ \\
\hline Hyperkinesias & $0(0 \%)$ & $18(100 \%)$ & $0(0 \%)$ & $20(100 \%)$ & $\mathrm{NS}$ \\
\hline Tremor & $0(66.7 \%)$ & $6(33.3 \%)$ & $1(5 \%)$ & $19(95 \%)$ & $\mathrm{P}=0.000^{*}$ \\
\hline Akathisia & $10(55.6 \%)$ & $8(44.4 \%)$ & $0(0 \%)$ & $20(100 \%)$ & $\mathrm{P}=0.000^{*}$ \\
\hline $\begin{array}{l}\text { Epileptic } \\
\text { Seizures }\end{array}$ & $0(0 \%)$ & $18(100 \%)$ & $0(0 \%)$ & $20(100 \%)$ & $\mathrm{NS}$ \\
\hline Paraesthesia & $2(11.1 \%)$ & $16(88.9 \%)$ & $1(5 \%)$ & $19(95 \%)$ & $\mathrm{P}=0.485$ \\
\hline
\end{tabular}

Table III: Autonomic side- effects observed in both the groups during the study

\begin{tabular}{|c|c|c|c|c|c|}
\hline Adverse Effect & \multicolumn{2}{|c|}{ Haloperidol } & \multicolumn{2}{|c|}{ Quetiapine } & T- test \\
\hline Autonomic & Present & Absent & Present & Absent & \\
\hline $\begin{array}{l}\text { Accommodation } \\
\text { Disturbance }\end{array}$ & $2(11.1 \%)$ & $16(88.9 \%)$ & $1(5 \%)$ & $19(95 \%)$ & $\mathrm{P}=0.005^{*}$ \\
\hline Increased Salivation & $6(33.3 \%)$ & $12(66.7 \%)$ & $0(0 \%)$ & $20(100 \%)$ & $\mathrm{P}=0.453$ \\
\hline Reduced Salivation & $2(11.1 \%)$ & $16(88.9 \%)$ & $4(20 \%)$ & $16(80 \%)$ & NS \\
\hline Nausea/Vomiting & $0(0 \%)$ & $18(100 \%)$ & $0(0 \%)$ & $20(100 \%)$ & NS \\
\hline Diarrhea & $0(0 \%)$ & $18(100 \%)$ & $0(0 \%)$ & $20(100 \%)$ & $\mathrm{P}=0.087$ \\
\hline Constipation & $0(0 \%)$ & $18(100 \%)$ & $3(15 \%)$ & $17(185 \%)$ & NS \\
\hline $\begin{array}{l}\text { Micturition } \\
\text { Disturbance }\end{array}$ & $0(0 \%)$ & $18(100 \%)$ & $0(0 \%)$ & $20(100 \%)$ & NS \\
\hline Polyuria / Polydipsia & $0(0 \%)$ & $18(100 \%)$ & $0(0 \%)$ & $20(100 \%)$ & $\mathrm{P}=0.485$ \\
\hline $\begin{array}{l}\text { Orthostatic } \\
\text { Dizziness }\end{array}$ & $6(33.3 \%)$ & $12(66.7 \%)$ & $15(75 \%)$ & $5(25 \%)$ & $\mathrm{P}=0.010^{*}$ \\
\hline Palpitations & $2(11.1 \%)$ & $16(88.9 \%)$ & $2(10 \%)$ & $18(90 \%)$ & $\mathrm{P}=0.911$ \\
\hline $\begin{array}{l}\text { Increased Tendency } \\
\text { to Sweating }\end{array}$ & $0(0 \%)$ & $18(100 \%)$ & $1(5 \%)$ & $19(95 \%)$ & $\mathrm{P}=0.336$ \\
\hline
\end{tabular}

\section{Neurological side effects}

In the present study, the category of neurological side effects clearly shows the preponderance of haloperidol over quetiapine. Parkinsonian side effects are significantly greater in the haloperidol group. The most predominant difference was in rigidity, which is $72.2 \%$ in haloperidol, while none of the patients receiving quetiapine showed rigidity. (Chi-square test gave P-0.000). Dystonia was observed with $6(33.3 \%)$ of the patients receiving haloperidol, while not observed in quetiapine group. (Chi- square test, $\mathrm{p}=0.005)$. Tremor was seen in $12(66.7 \%)$ in haloperidol, while only $1(5 \%)$ patient on quetiapine showed tremor. (Chi-square test $\mathrm{p}=0.000)$. Akathisia was seen in $10(55.6 \%)$ in haloperidol group while not observed in quetiapine, (Chi- square test $\mathrm{p}=0.000$ ) Hypokinesia was seen in haloperidol 
$7(38.9 \%)$, while only one of the patient $1(5 \%)$ receiving quetiapine showed Hypokinesia. (Chi- square test $\mathrm{p}=0.011$ ). Hyperkinesia not seen in any of the group. Epiletic seizures were not seen. Paraesthesia occurred in 2(11.1\%) and $1(5 \%)$ in haloperidol and quetiapine but not found to be significant.

\section{Psychiatric side effects}

In this category, Asthenia was seen mostly in haloperidol $10(55.6 \%)$ and only in $3(15 \%)$ in the patients receiving quetiapine was statistically significant as, $\mathrm{p}=0.009$. Sleepiness was seen in $4(22.2 \%)$ and $9(45 \%)$ of the patients receiving haloperidol and quetiapine respectively. Increased duration of sleep was seen more in quetiapine group $7(35 \%)$ than $1(5.6 \%)$ in haloperidol, which was statistically significant, $(* \mathrm{p}=0.026)$. Failing memory was not seen in either group. Depression was not seen in either group. Tension was seen in $3(16.7 \%)$ in the haloperidol group while not appreciated in quetiapine group. Reduced duration of sleep was not observed with any of the groups. No increased dream activity or emotional indifference was seen in either group.

\section{Autonomic side effects}

In this category-the most troublesome side effect in quetiapine group emerged to be orthostatic dizziness. Orthostatic dizziness was seen in $6(33.3 \%)$ and $15(75 \%)$ of the patients receiving haloperidol and quetiapine respectively, which was statistically significant $\mathrm{p}=0.01$. Increase salivation was not observed with quetiapine with quetiapine while with haloperidol $6(33.3 \%)$ had increased salivation (chi- square$\mathrm{p}=0.005)$ which was significant. Reduced salivation was seen in $2(11.1 \%)$ and $4(20 \%)$ of the patients receiving haloperidol and quetiapine .Accommodation distruance was seen in $2(11.1 \%)$ of the patients receiving haloperidol, and $1(5 \%)$ receiving quetiapine. $3(15 \%)$ receiving quetiapine and none receiving haloperidol complained of constipation. Palpitation was complained by $2(11.1 \%)$ and $2(10 \%)$ among the patients receiving haloperidol and quetiapine respectively. Increased tendency to sweating was noticed. In quetiapine grouping one patient $1(5 \%)$ while not observed in haloperidol group.. None of the patients receiving haloperidol or quetiapine had nausea. Diarrhea was not seen in either group. Polyuria was not complained of in either group.

\section{Discussion:}

In the treatment with antipsychotic molecules, the side effect profile is equally important as the efficacy, because the short term and long term outcomes of the drug might make the patient worse than the disease itself Amongst other things the neurological side effects are most important for the patient to continue their medicines ${ }^{1,5,6}$.

In the present study the catgory of neurological of psychic and neurological and autonomic side effects clearly show the preponderance of haloperidol to quetiapine in almost all the side effects, except for the ortostatic dizziness, constipation, reduced salivation, asthenia, concentration difficulties, and increased duration of sleep. This result is almost in consistent with the findings suggested by Sacchetti et al, Mullen et al, Cupillari, Kristina and Carlsson, and and Marder and Meibach',6,8,9.

Parkinsonian side effects are significantly greater in the haloperidol group. The most important difference was in dystonia, and rigidity, followed by tremor. Though there is not siginificant statistical differences, 
haloperidol induced more hyperkinesia and epileptic seizures than quetiapine.

Since dystonia is extremely disturbing for the patients, this side effect is one of the major drawback in conventional antipsychotic treatment and reason for noncompliance $^{1,2,5}$.

Haloperidol also induced more akathisia, which is more difficult to endure than any of the symptoms for which the patient was originally treated $^{5,6}$. There was also a remarkable consistency in the results of EPS and the use of antiparkinsonian medication. These results are consistent with many other trials.

\section{Conclusion and Summary:}

\section{References:}

1 Borison RL, Arvantitis LA, Miller BG, and the US SEROQUEL Study Group (1996): ICI 204, 636, an atypical antipsychotic Efficacy and safety in a multicenter, placebo- controlled trial in patients with schizophrenia, J Clin Psychopharmacol 16; 158-168.

2. Copolv DL, Link CGG, Kowalcyk B A multicentre, double-blind, randomized comparison of quetiapine (ICI 204,636'Seroquwl) and haloperidol in schizophrenia. Psychol Med 2000 Jan: 30(1):95-105

3. Emsely RA, Rainwalla J, Bailey PJ, et al. A comparison of effects of quetiapine ('Seroquel') and haloperidol in schizophrenic patients with a history of and a demonstrated, partial response to conventional antipsychotic treatment: Prize Study Group. Int Clin Psychopharmaco 2000May:15(3): 121-31
Quetiapine has a better tolerability profile than haloperidol. In haloperidol majority of side effects were severe mostly neurological, such as Rigidity dystonia, tremor, akathisia, hypokinesia, asthenia, and increased salivation, while in quetiapine major side effects noticed were orthostatic dizziness, increased duration of sleep, most of side effects were mild to moderate in intensity. The adjunctive use of anti-parkinsonian medication is lesser in quetiapine than in haloperidol. Also, the better and quicker action of quetiapine on negative ansdd cognitive symptoms may lead to better improvement in social functioning and improved treatment compliance compared to haloperidol.

4. Saller C.F.Salama I Seroquel: biochemical profile of a potential atypical antipsychotic. Psychopharmacology 1993:112:285-292.

5. Zhong X, Sweitzer D Russo J, et al. To compare the efficacy, safety, and tolerability of quetiapine and risperidne in treating patients with schizophrenia (abstract no. P.2.140). Eru Neuronopsychopharmacol 2003, 13 suppl 4, S340

6. Sacchetti E, Balsecchi P, Regini C, et al. Comparison of que-tiapine, olanzapine and risperdone in patients with schizo-phrenia: interim results of a randomized, raterblinded study (abstract no. P 2. 162). Plus poster presented at the $16^{\text {th }}$ Congress of the European College of Neuropsycopharmacology: 2003 Sep 20-24: Prague. Eur Neuropsychopharmacol 2003:13 Suppl 4: S350

7. Mullen J, Jibsom MD, Sweitzer D, et al. A comparison of the relative safety, efficancy, and tolerability of quetiapine and 
risperidone in outpatients with schizophrenia and other psychotic disorders: the Quetiapine Experience with Safety and Tolerability (QUEST) study.Clin Ther 2001 Nov: 23911) : 1839-54.

8. Cupillari M,Use of quetiapine in psychotic disorders: evaluation of the effects of the treatment using the drug attitude inventory 30(DA130) (abstract no. P.2.021) Plus poster presented at the $16^{\text {th }}$ Congress of the Eurpean College of Neuro psychopharmacology: 2003 Sep, 20-24. Prague. Eur Neuropsy-chopharmacol 2003. 13 Suppl. 4. S287

9. Kristina Timdahl, Carlsson \& Stening (An analysis of safety and tolerability data from controlled, comparative studies of quetiapine in patients with schizophrenia, focusing on extrapyramidal symptoms.) hum. Psychopharmacol Clin Exp 2007:22: $315: 325$

Adress of Correspondance: Dr. Naba Raj Koirala, Professor and Head, Department of Psychiatry and Mental Health, Nobel Medical College,Biratnagar.E-mail:drnabaraj@yahoo.com 